\title{
Gynaecological and obstetric bleeding in moderate and severe von Willebrand disease
}

\author{
Eva M. de Wee'; H. Marieke Knol2,3; Eveline P. Mauser-Bunschoten'; Johanna G. van der Bom ${ }^{5,6}$; Jeroen C. J. Eikenboom ${ }^{5,7}$; \\ Karin Fijnvandraat ${ }^{8}$; Arja de Goede-Bolder ${ }^{9}$; Britta Laros-van Gorkom ${ }^{10}$; Paula F. Ypma ${ }^{11}$; Sonja Zweegman ${ }^{12}$; Karina Meijer ${ }^{2}$; \\ Frank W. G. Leebeek'; for the WiN study group \\ ${ }^{1}$ Hematology, Erasmus University Medical Center Rotterdam, Netherlands; ${ }^{2}$ Hematology, University Medical Center Groningen, Netherlands; ${ }^{3}$ Gynaecology, University Medical \\ Center Groningen, Netherlands; ${ }^{4}$ Van Creveldkliniek and Hematology, University Medical Center Utrecht, Netherlands; ${ }^{5}$ Einthoven Laboratory for Experimental Vascular Medicine, \\ Leiden University Medical Center, Netherlands; ${ }^{6}$ Department of Clinical Epidemiology, Leiden University Medical Center, Netherlands; ${ }^{7}$ Thrombosis and Hemostasis, Leiden \\ University Medical Center, Netherlands; ${ }^{8}$ Pediatric Hematology, Emma Children's hospital AMC, Amsterdam, Netherlands; ${ }^{9}$ Pediatrics, Erasmus MC, Sophia Children's hospital, \\ Rotterdam, Netherlands; ${ }^{10} \mathrm{Hematology}$, Radboud University Nijmegen Medical Centre, Nijmegen, Netherlands; ${ }^{11}$ Hematology, HagaZiekenhuis, The Hague, Netherlands; \\ ${ }^{12}$ Hematology, VU University Medical Center, Amsterdam, Netherlands
}

\begin{abstract}
Summary
A nation-wide cross-sectional study was initiated to assess gynaecological and obstetrical symptoms in an unselected cohort of women with moderate and severe von Willebrand disease (VWD) in the Netherlands. A total of 423 women aged $\geq 16$ years were included. Bleeding severity was measured using the Tosetto Bleeding Score (BS). Menorrhagia, defined as occurrence of $\geq 2$ menorrhagia symptoms, was reported by $81 \%$. Of all VWD women, $78 \%$ received any kind of treatment for menorrhagia and $20 \%$ underwent a hysterectomy predominantly because of severe menstrual bleeding. Over half of the women reported more blood loss than can be expected with a normal delivery. In $52 \%$ of reported pregnancy losses curettage was needed because of bleeding.
\end{abstract}

Mean number of live births was 1.9, which is comparable with the general Dutch population. In conclusion, women with moderate or severe VWD frequently have menorrhagia in need of treatment, and $20 \%$ of the VWD women underwent a hysterectomy. Bleeding complications occurred in over $50 \%$ of the women after childbirth or pregnancy loss. Progeny seems not to be affected in women with moderate or severe VWD.

\section{Keywords}

Bleeding, menorrhagia, postpartum haemorrhage, von Willebrand disease, hysterectomy

\section{Correspondence to:}

Prof Frank W.G. Leebeek, MD, PhD

Erasmus University Medical Center

PO Box 2040, 3000 CA Rotterdam, Netherlands

Tel.: +31 10 7034935, Fax: +31 107035814

E-mail: f.leebeek@erasmusmc.nl
Received : March 17, 2011

Accepted after minor revision: July 29, 2011

Prepublished online: September 22, 2011

doi:10.1160/TH11-03-0180

Thromb Haemost 2011; 106: 885-892

\section{Introduction}

von Willebrand disease (VWD) is caused by defects in or reduced levels of Von Willebrand Factor (VWF). It is the most common inherited bleeding disorder and affects $0.5-1 \%$ of the population, although not all patients with low VWF levels have clinically relevant bleeding episodes $(1,2)$.

Patients with VWD frequently have bleeding episodes, varying from gum bleeds and epistaxis to intestinal bleeding. In theory, men and women are equally likely to be affected, but in women VWD is more often clinically manifest because of the bleeding challenges that are associated with menstruation and childbirth (1). Tosetto et al. have developed a bleeding score (BS) to quantify the number and severity of bleeding symptoms (2).Two of the 12 items of the BS include menorrhagia and postpartum haemorrhage (PPH). We used the BS, a validated and commonly used instrument, to determine the severity of menorrhagia and $\mathrm{PPH}$.
The majority of published studies investigating the prevalence of gynaecological symptoms in women with VWD are case series of a relatively small number of women (3-7). In addition these women had predominantly type 1 or mild VWD. In these studies women with VWD frequently have menorrhagia with reported prevalence ranging from $74-92 \%$, which may impair quality of life (QoL) $(4,5,8)$. Also increased absence from school or work during menstruation is reported $(5,6,10-13)$. One study reported that women with VWD more often underwent hysterectomy than women without VWD (9). The above mentioned studies may suffer from selection bias given the fact that patients seeking medical attention for bleeding and menorrhagia have predominantly been included.

Therefore the aim of our study was to assess gynaecological and obstetrical symptoms in a large unselected cohort of women with moderate or severe VWD who participated in a nation-wide study. 


\section{Methods}

\section{Participants}

We performed a nation-wide cross-sectional study among patients with moderate and severe VWD in the Netherlands, the "Willebrand in the Netherlands" (WiN) study. Data on gynaecological and obstetric bleeding were obtained retrospectively. Patients were recruited at all 13 Hemophilia Treatment Centers (HTCs) in the Netherlands. We included patients diagnosed with type 1, type 2 and type 3 VWD who fulfilled both of the following inclusion criteria: 1) haemorrhagic symptoms or a family history of von Willebrand disease; 2) historic levels of VWF antigen (VWF:Ag) $\leq 30 \mathrm{U} / \mathrm{dl}$ and/or VWF activity (VWF ristocetin cofactor activity (VWF:RCo) and/or VWF collagen binding assay (VWF:CB)) $\leq 30$ $\mathrm{U} / \mathrm{dl}$ and/or FVIII:C $\leq 40 \mathrm{U} / \mathrm{dl}$ at least once. Classification of VWD into type 1,2 and 3 was based on VWF parameters measured in laboratories of the various HTCs and according to classification guidelines $(10,11)$. Patients with mild VWD were excluded, as were patients with other congenital disorders of haemostasis resulting in a haemorrhagic diathesis.

For the present analyses we selected all women aged 16 years and older. Data were obtained between October 2007 and October

Table 1: Definition of menorrhagia (A) and classification of severity of menorrhagia and postpartum haemorrhage (B), according to the Tosetto Bleeding Score.

\begin{tabular}{l}
\hline A) Menorrhagia: $\geq 2$ symptoms at the time of study or in the \\
past \\
\hline - subjective excessive menstrual bleeding \\
- loss of blood clots during menstrual bleeding \\
- requirement of oral iron therapy or blood transfusion \\
- heavy menstrual flow that interferes with daily life \\
- menstrual period that lasts longer than 7 days \\
\hline B) Severity of bleeding symptoms* \\
\hline Severity of menorrhagia (BSmenorrhagia) \\
\hline Score 0: No menorrhagia \\
Score 1: Consultation only \\
Score 2: Antifibrinolytics or pill use \\
Score 3: Dilatation and curettage or iron therapy \\
Score 4: Blood transfusion, FVIII/VWF concentrate, desmopressin or hysterec- \\
tomy \\
\hline Severity of PPH (BS-PPH)* \\
\hline Score -1: No bleeding in at least two deliveries \\
Score 0: No deliveries or no bleeding in one delivery \\
Score 1: Consultation only \\
Score 2: Dilatation and curettage, iron therapy, antifibrinolytics \\
Score 3: Blood transfusion or FVIII/VWF concentrate or desmopressin \\
Score 4: Hysterectomy \\
\hline * BS=bleeding score; scores are derived from the Tosetto Bleeding Score (18). \\
PPH= postpartum haemorrhage. \\
\hline
\end{tabular}

2009. The Medical Ethical Committees at all participating HTCs approved this study, and written informed consent was obtained from all study participants.

\section{Assessment methods}

All participants completed an extensive questionnaire, which contained questions on bleeding episodes, treatment of VWD, side effects of treatment, concomitant disease, and employment (17). The BS was incorporated into this questionnaire.

The BS was used as previously described for bleeding severity in type 1 VWD by Tosetto et al. (2). It systematically evaluates bleeding symptoms, and accounts for both the number and severity of the bleeding symptoms. The severity and frequency of 12 items are scored on a scale ranging from -1 to 4 points. Higher scores reflect more severe/frequent bleeding. The total of all 12 items results in the BS (range 3 to 45 ).

\section{Definitions}

Severe VWD was defined as the presence of at least one of the following laboratory abnormalities: VWF:Ag $\leq 10 \mathrm{U} / \mathrm{dl}$, and/or VWF:RCo $\leq 10 \mathrm{U} / \mathrm{dl}$, and/or FVIII:C $\leq 20 \mathrm{U} / \mathrm{dl}$. Moderate VWD was defined as VWF:Ag 10-30 U/dl, and/or VWF:RCo 10-30 U/dl, and/or FVIII:C 20-40 U/dl (12).

Menorrhagia was defined as the occurrence of at least two of the symptoms listed in Table 1A (13-15). Severity of menorrhagia was determined according to the menorrhagia items of the Tosetto Bleeding Score (BSmenorrhagia) (2). The score for this item ranges from 0 to 4 ( $>$ Table $1 \mathrm{~B})$.

Severity of bleeding complications following childbirth was determined according to the PPH item of the Tosetto Bleeding Score (BS-PPH) (2). The score for this item ranges from -1 to 4 (-Table 1B).

Foetal loss was defined as spontaneous miscarriages, foetal death and intrauterine death.

\section{Laboratory measurements of VWD}

Historic measured VWF and FVIII levels in the Hemophilia Treatment Centers were used as inclusion criteria for the WiN study, and patients with at least one measurement of VWF or FVIII below 30 $\mathrm{U} / \mathrm{dl}$ or $40 \mathrm{U} / \mathrm{dl}$, respectively, were included.

Peripheral venous blood was collected at inclusion of the study. Plasma levels of VWF antigen (VWF:Ag), VWF collagen binding (VWF:CB), VWF activity (VWF:Act) and FVIII activity (FVIII:C) were measured centrally in the Erasmus University Medical Center, Rotterdam, The Netherlands. VWF:Ag level was measured with an in-house ELISA using a polyclonal rabbit anti-human 
Figure 1: Flow chart of study inclusion.

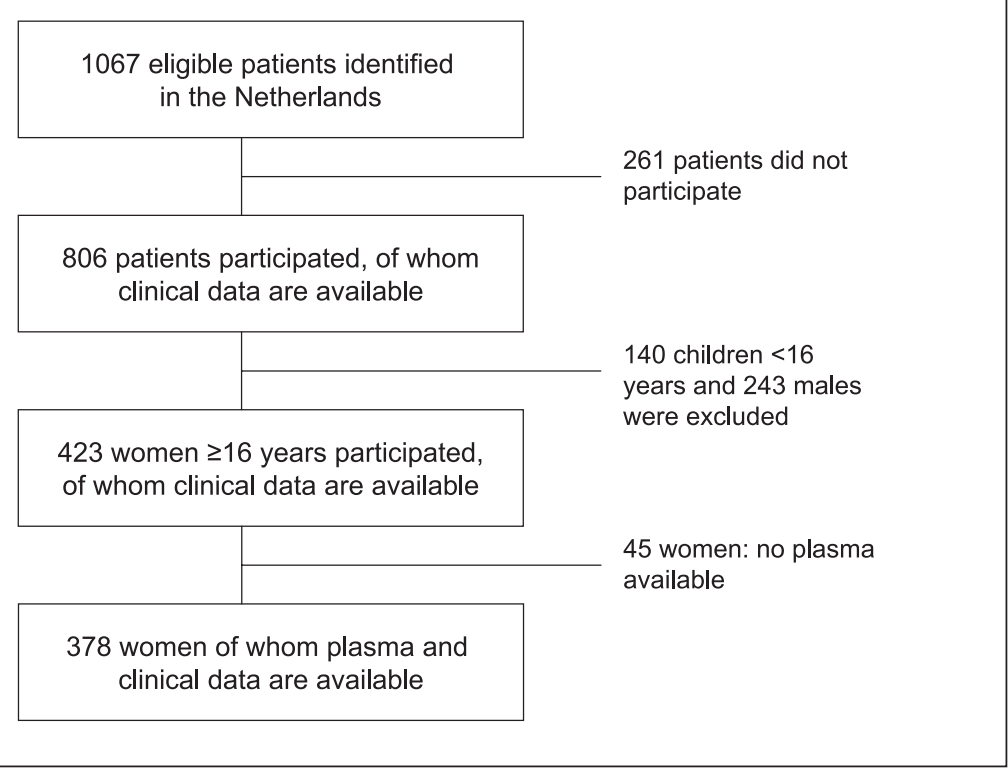

VWF antibody (DakoCytomation, Glostrop, Denmark) for capturing and a HRP-conjugated anti-human VWF antibody (DakoCytomation) for detecting. VWF:CB level was measured with an in-house ELISA using collagen type 1 (Sigma-Aldrich, St Louis, MO, USA) for capturing and a HRP-conjugated anti-human VWF antibody (DakoCytomation) for detecting. To assess VWF activity we have used an VWF:Act assay that measures the ability of VWF to bind glycoprotein (GP)Ib $\alpha$. The VWF:Act assay uses latex particles coated with a monoclonal murine antibody direct against the GPIb $\alpha$ binding domain of VWF (Instrumentation Laboratory B.V, Breda, The Netherlands). These latex particles were incubated with the patient plasma and agglutination of the particles, proportionally to the GPIb $\alpha$ binding activity of VWF, was measured (16). In the Erasmus University Medical Center Rotterdam we have validated this test and compared it with the VWF:RCo activity test. We obtained a Spearman correlation coefficient of 0.942 FVIII:C was measured in a one-stage clotting assay (TriniCLOT, Biomerieux, Marcy l'Etoile, France) with FVIII-deficient plasma (Biopool, Umea, Sweden). Multimeric pattern was evaluated by low resolution $0.9 \%$ agarose (Bio-Rad Laboratories, Hercules, CA, USA) gel electrophoresis followed by capillary Western blotting (17). VWF multimer patterns were evaluated by two independent reviewers (HCJE and FWGL). VWF multimers were classified as either abnormal, normal or absent by comparison with the commercial reference plasma (Normal reference plasma, Precision biologic, Kordia, Leiden, Netherlands). Abnormal multimers were defined as a deviation from a normal distribution; according to the MCMDM1VWD study (18).

Determination of type of VWD into type 1, type 2 and type 3 VWD and subclassification was based on the centrally determined VWF and FVIII parameters, according to ISTH (International Society on Thrombosis and Haemostasis) guidelines $(10,11,19)$.

\section{Statistical methods}

Continuous variables, expressed as medians (ranges) were used for age of menarche, duration of period, number of days of heavy menstrual bleeding, and data on deliveries and PPH. The chisquare test was performed to analyse differences between the prevalence of symptoms and bleeding scores between subgroups. ANOVA test was used to analyse differences in age and duration of menstrual bleeding, and for data on deliveries and PPH. Significant differences were defined as a $\mathrm{p}$-value $\leq 0.05$.

\section{Results}

A total of 423 women were included in the study, see Fig. 1. - Table 2 represents the patient characteristics. Median age was 46 (range 16-83) years. A total of $242(64 \%)$ women had type 1 VWD, $120(32 \%)$ had type 2 VWD, and $16(4 \%)$ had type 3 VWD.

\section{Menorrhagia in women with moderate or severe VWD}

Median age of menarche was 13 years (interquartile range [IQR] 12-14) ( Table 3). The median duration of menstrual bleeding of the women included in this study was seven days. Menorrhagia, defined as occurrence of $\geq 2$ menorrhagia symptoms, was reported by $81 \%$ of the women (Table 3). The two most frequent symptoms were excessive menstrual bleeding $(82 \%)$ and loss of blood clots (80\%). No differences were observed for type 1, type 2 and type 3 VWD. 
Table 2: Patient characteristics of the women included in the study $(n=423)$.

\begin{tabular}{|c|c|c|c|}
\hline Age & median, range & 46 & $16-83$ \\
\hline \multirow[t]{7}{*}{ VWD type* } & $1(n, \%)$ & 242 & $64 \%$ \\
\hline & $2(n, \%)$ & 120 & $32 \%$ \\
\hline & $2 A(n)$ & 83 & \\
\hline & $2 B(n)$ & 15 & \\
\hline & $2 M(n)$ & 14 & \\
\hline & $2 N(n)$ & 8 & \\
\hline & $3(n, \%)$ & 16 & $4 \%$ \\
\hline VWF:Ag* & median U/dl, IQR & 33 & 21 to 47 \\
\hline VWF:CB* & median U/dl, IQR & 28 & 11 to 57 \\
\hline VWF:Act* & median U/dl, IQR & 28 & 12 to 59 \\
\hline FVIII:C* & median U/dl, IQR & 56 & 37 to 80 \\
\hline \multirow[t]{2}{*}{ VWD severity* } & severe VWD & 121 & $32 \%$ \\
\hline & moderate VWD & 257 & $68 \%$ \\
\hline Bleeding score & median, range & 12 & -1 to 35 \\
\hline
\end{tabular}

Eighty-five percent of all VWD women had consulted their general practitioner or gynaecologist because of menorrhagia, including 24 women who did not qualify as "menorrhagia" according to our strict definition.

\section{Treatment of menorrhagia in patients with moderate or severe VWD}

Nearly all women with menorrhagia (99\%) had used some treatment for menorrhagia. Figure 2 shows which treatment women with moderate or severe VWD received because of menorrhagia. Most women with menorrhagia use or have used hormonal contraceptives (hormone therapy, oral contraceptives, or levonorgestrel intrauterine device) to control menstrual blood loss (68\%). In $10 \%$ of the women desmopressin was given because of menorrhagia. Eleven percent of the women received a blood transfusion at least once because of anaemia due to menorrhagia. Fiftysix percent of the women with type 3 VWD received a blood transfusion, FVIII/VWF concentrate, or underwent a hysterectomy because of menorrhagia.

Of all included women with VWD, 20\% (n=84) underwent a hysterectomy. In the group of women $>40$ years $28 \%$ underwent a hysterectomy. Of the women with type 1, type 2, and type 3 VWD $24 \%, 14 \%$ and $13 \%$, respectively, underwent a hysterectomy. In 31 $(37 \%)$ of the women VWD was diagnosed after the hysterectomy, in 29 (35\%) before hysterectomy, whereas in the other women this was unknown. The median age at the time of hysterectomy was 37 years (range 26-54). Median age at the time of hysterectomy did not differ for women who were diagnosed before (38, range 27-51) or after $(37$, range $26-53)$ the hysterectomy $(p=0.358)$. Data on surgery-related bleeding was available in 50 hysterectomies, of which 29 were complicated by a bleeding (58\%). A hysterectomy was more often complicated by bleeding if VWD was not yet diagnosed before the hysterectomy. A hysterectomy was performed in

Table 3: Menorrhagia in women with moderate or severe VWD.

\begin{tabular}{|c|c|c|c|c|c|c|c|c|c|c|}
\hline \multirow[b]{2}{*}{ Age of menarche } & \multirow[b]{2}{*}{ median, IQR } & \multicolumn{2}{|c|}{ Total $(n=423)$} & \multicolumn{2}{|c|}{ Type $1(n=242)$} & \multicolumn{2}{|c|}{ Type $2(n=120)$} & \multicolumn{2}{|c|}{ Type $3(n=16)$} & \multirow{2}{*}{$\frac{\text { P-value * }}{0.63}$} \\
\hline & & 13 & $12-14$ & 13 & $12-14$ & 13 & $12-14$ & 13 & $12-14$ & \\
\hline Duration period & median, IQR & 7 & $6-8$ & 7 & $6-8$ & 7 & $6-8$ & 7 & $7-10$ & 0.76 \\
\hline Number of days heavy menstrual bleeding & median, IQR & 4 & $3-5$ & 4 & $3-6$ & 4 & $3-5$ & 4 & $3-6.5$ & 0.41 \\
\hline Menorrhagia symptoms & median, IQR & 3 & $2-4$ & 3 & $2-4$ & 3 & $2-4$ & 3 & $1-4$ & 0.52 \\
\hline Excessive menstrual bleeding & $n, \%$ & 347 & $82 \%$ & 202 & $83 \%$ & 98 & $82 \%$ & 13 & $81 \%$ & 0.19 \\
\hline Loss of blood clots & $n, \%$ & 338 & $80 \%$ & 196 & $81 \%$ & 100 & $83 \%$ & 10 & $63 \%$ & 0.48 \\
\hline Requirement of iron or blood transfusion & $n, \%$ & 184 & $44 \%$ & 105 & $43 \%$ & 60 & $50 \%$ & 10 & $63 \%$ & 0.08 \\
\hline Heavy menstrual flow that interferes with daily life & $\mathrm{n}, \%$ & 192 & $45 \%$ & 110 & $45 \%$ & 58 & $48 \%$ & 7 & $44 \%$ & 0.77 \\
\hline Menstrual period that lasts $>7$ days & $n, \%$ & 150 & $36 \%$ & 81 & $33 \%$ & 51 & $43 \%$ & 6 & $38 \%$ & 0.16 \\
\hline Menorrhagia $\geq 2$ symptoms present & $n, \%$ & 342 & $81 \%$ & 196 & $81 \%$ & 99 & $83 \%$ & 12 & $75 \%$ & 0.76 \\
\hline Menorrhagia severity & median, IQR & 3 & $2-4$ & 3 & $2-4$ & 3 & $2-4$ & 3 & $2-4$ & 0.10 \\
\hline 0: no menorrhagia & $n, \%$ & 64 & $15 \%$ & 41 & $17 \%$ & 13 & $11 \%$ & 1 & $6 \%$ & \\
\hline 1: consultation only & $n, \%$ & 29 & $7 \%$ & 19 & $8 \%$ & 5 & $4 \%$ & 1 & $6 \%$ & \\
\hline 2: antifibrinolytics or pill use & $n, \%$ & 98 & $23 \%$ & 46 & $19 \%$ & 31 & $26 \%$ & 5 & $31 \%$ & \\
\hline 3: dilatation and currettage or iron therapy & $\mathrm{n}, \%$ & 121 & $29 \%$ & 74 & $31 \%$ & 37 & $31 \%$ & 3 & $19 \%$ & \\
\hline $\begin{array}{l}\text { 4: blood transfusion, FVIII/VWF concentrate, desmo- } \\
\text { pressin or hysterectomy }\end{array}$ & $\mathrm{n}, \%$ & 111 & $26 \%$ & 62 & $26 \%$ & 34 & $28 \%$ & 9 & $56 \%$ & \\
\hline
\end{tabular}


$68 \%$ of the women because of menorrhagia. In the other women it is unknown whether bleeding was the cause of the hysterectomy. Two women underwent endometrial ablation.

\section{Pregnancies and bleeding in patients with moderate or severe VWD}

Of the total cohort of 423 women 314 (74\%) had ever been pregnant. The mean number of live births per woman with moderate or severe VWD above the age of 40 years is 1.9. The 314 women had 691 deliveries. Of the 314 women 159 (51\%) reported more blood loss than can be expected with a normal delivery (see Table 4). This was not different in women who gave birth recently or decades ago. In women aged $16-40$ years, 41 to 60 years and $>60$ years a PPH occurred in $46 \%, 51 \%$ and $55 \%$, respectively ( $\mathrm{p}=0.610$ ). In $77(11 \%)$ of the 691 deliveries a blood transfusion was given because of PPH.

Twenty-seven percent of the primary PPHs (within 24 hours after childbirth) occurred in women who received prophylactic FVIII/VWF concentrate or desmopressin. The severity of PPH is reflected in Tosetto bleeding score on PPH (BS-PPH). Of the 314 women who had been pregnant, $101(33 \%)$ had a BS-PPH of $\geq 2$, indicating that they were treated for $\mathrm{PPH}$. A blood transfusion, FVIII/VWF concentrate or desmopressin was needed in 90/314 $(29 \%)$ women, and three women (1\%) underwent a hysterectomy because of a massive PPH.

BS-PPH was significantly different between women with moderate and severe VWD: women with moderate VWD had a median BSPPH of 0 (IQR -1 to 4), whereas women with severe VWD had a median BS-PPH of 1 (range -1 to 3 ) ( $\mathrm{p}=0.046)$. We found an association between VWF levels, FVIII level and BS-PPH. Patients with the lowest VWF and FVIII levels had the highest BS for the item PPH. Women with VWF:Ag, VWF:Act or FVIII levels < 10 IU/dl compared to women with levels $\geq 10 \mathrm{IU} / \mathrm{dl}$, had a $1.0(0.3-1.7), 0.5(0.0-0.9)$, and $1.8(0.6-3.0)$ point BS-PPH increase, respectively.

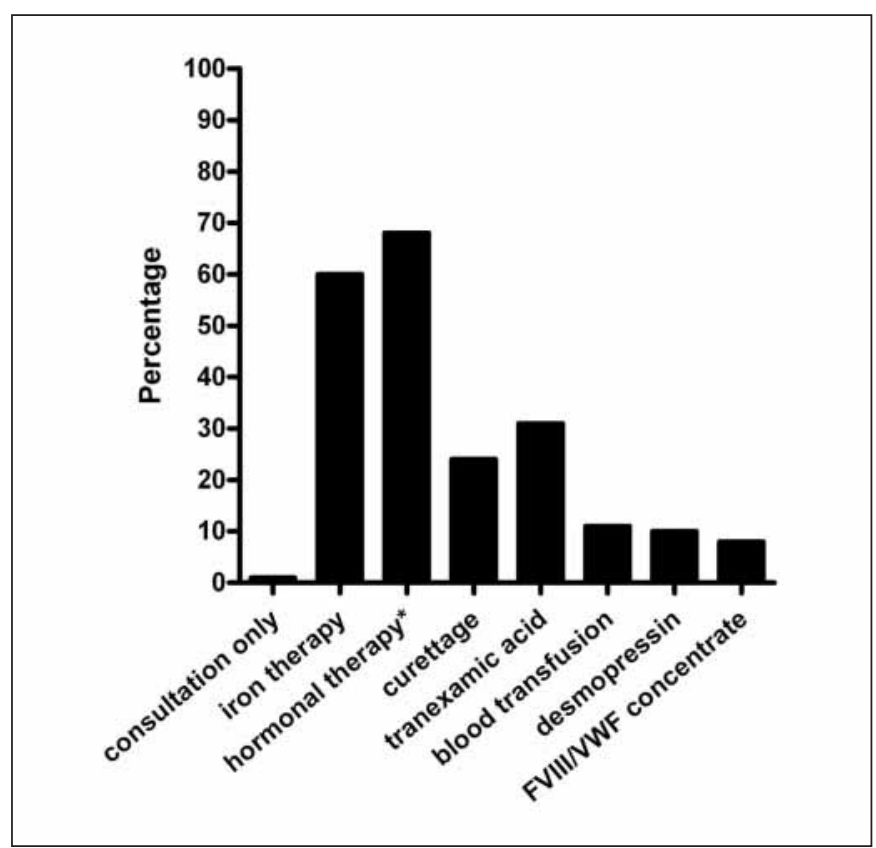

Figure 2: Treatment of menorrhagia in women with moderate or severe VWD $(n=342)$. *Hormone therapy, oral contraceptives, hormone releasing IUD. Patients may have used more than one treatment option.

\section{Spontaneous abortion, foetal death and intrauterine death in moderate or severe VWD}

We collected data on elective abortions, spontaneous miscarriages and foetal deaths. Twenty women did not fill in this part of the questionnaire, therefore data were available for 294 of the 314 women who have been pregnant. Of these, 115 women (39\%) had a total of 201 pregnancy losses (elective abortions, spontaneous miscarriages and foetal deaths). In $52 \%$ of the pregnancy losses curettage was needed because of bleeding.

Table 4: Bleeding complications during deliveries in women with VWD who have been pregnant at least once.

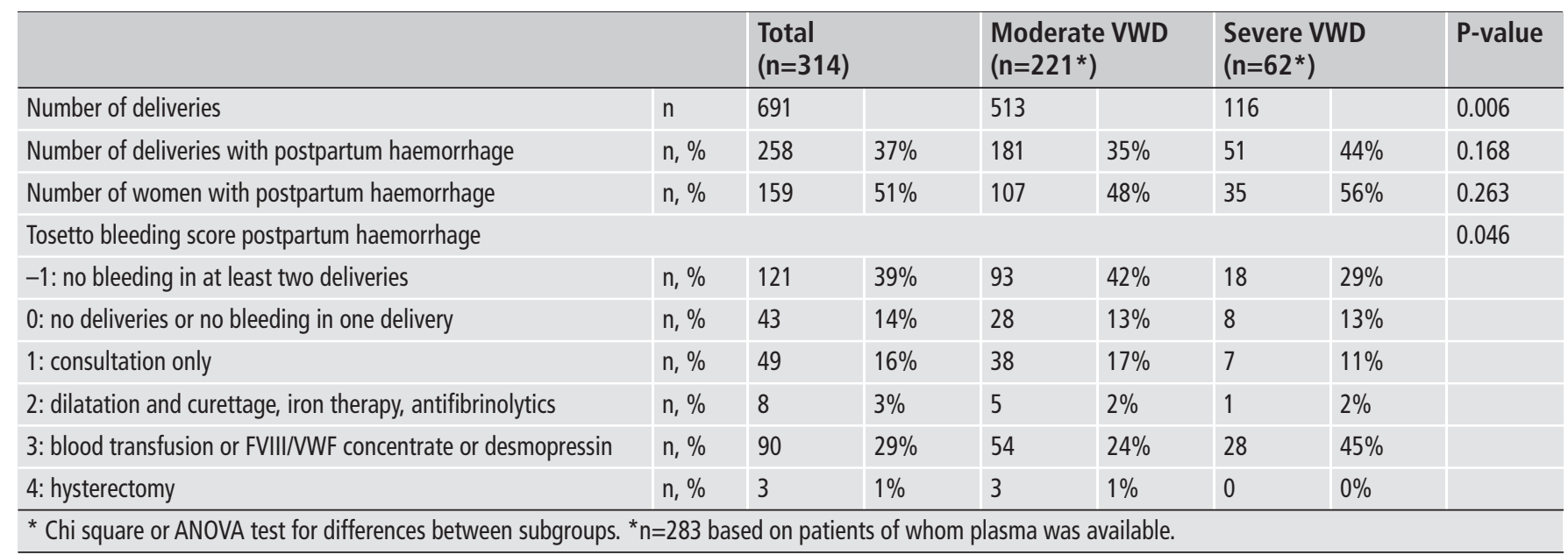




\section{Discussion}

In this nationwide study of a large unselected cohort of 423 women with moderate to severe VWD in the Netherlands, we have demonstrated a very high prevalence of menorrhagia. Nearly $80 \%$ of all the VWD women had used medication or underwent an intervention because of menorrhagia. Of all included women with VWD, $20 \%$ underwent a hysterectomy. Moreover, a high incidence of bleeding complications associated with pregnancies was observed. Thirty-nine percent of these women had a pregnancy loss, half of the women needed curettage because of bleeding after pregnancy losses. Progeny was comparable with the general Dutch population.

In this largest cohort of women with VWD described so far, including the majority of all women with moderate to severe VWD in the Netherlands, $81 \%$ reported the occurrence of two or more symptoms of menorrhagia and $85 \%$ sought medical attention for menorrhagia. This is comparable with other, smaller studies about menorrhagia in women with $\operatorname{VWD}(4,5,8,20)$. These are very high numbers in comparison to the general population in which $5-10 \%$ of women in reproductive age has sought medical attention for menorrhagia (21). There is a discrepancy between the percentage of women consulting a physician for menorrhagia (85\%) and the percentage of women with menorrhagia $(81 \%)$. Probably most of the women have menorrhagia, but did not fulfil the strict definition of "menorrhagia" we used in our study. In addition, women may subjectively perceive their menses as normal when mothers or sisters also have menorrhagia.

The high number of hysterectomies (20\%) in our VWD cohort is of particular concern. The proportion of hysterectomies is nearly twice as high as that previously reported in a Dutch study on women with chronic menorrhagia. In this study $11 \%$ of the women underwent a hysterectomy at a median age of 42 (22). The women in our study underwent the hysterectomy at a younger age (median 38 years), which is comparable with other studies on

\section{What is known about this topic?}

- von Willebrand disease (VWD) is diagnosed more often in women, due to the gynaecological and obstetric bleeding complications.

- Women with VWD type 1 frequently have menorrhagia which may impair quality of life.

\section{What does this paper add?}

- This study shows that gynaecological and obstetrical bleeding symptoms occur frequently in women with moderate and severe VWD.

- Seventy-eight percent of women with VWD seek medical attention for menorrhagia.

- A high percentage $(20 \%)$ of women with moderate to severe VWD undergo hysterectomy predominantly because of excessive menstrual bleeding.

- Women with moderate to severe VWD have a similar number of live births compared to the general population. women with $\operatorname{VWD}(4,6,8,20)$. A hysterectomy was complicated by bleeding more often if VWD had not yet been diagnosed. It is therefore of utmost importance that gynaecologists consider inherited bleeding abnormalities including VWD because in these women other treatment options, i.e. intranasal desmopressin and/ or tranexamic acid, might have resulted in less menstrual blood loss. In case surgery is still needed, desmopressin or FVIII/VWF concentrate can be given perioperatively to prevent bleeding complications. Fortunately, the high proportion of hysterectomies does not seem to reduce the progeny, as the number of children born in this cohort is similar to the general population.

Despite the increased awareness of bleeding problems in women with VWD in the last decades $(13,23,24), \mathrm{PPH}$ is still a major concern in these women. Treatment options like FVIII/VWF concentrate have become available, nevertheless we observed no reduction in $\mathrm{PPH}$ over the last decades. A blood transfusion after delivery was more often needed in VWD women (11\% of all deliveries) compared to the general population in which the incidence of blood transfusion after vaginal delivery and caesarean section is $1 \%$ and $1-7 \%$, respectively (25). In our study we used retrospective data, therefore it is impossible to definitely confirm the diagnosis of PPH, furthermore it is known that surveys on $\mathrm{PPH}$ show higher numbers than discharge summaries (26). Remarkably, improvement of care and guidelines has not decreased the frequency of PPH. The cause of PPH in women who received prophylactic treatment was unknown. Prospective studies are needed in order to improve outcome and to optimise current treatment guidelines (27).

A main concern of many women with VWD is whether they have lower rates of conception or a higher chance of miscarriages or spontaneous abortions. Our study revealed a mean number of live births of 1.9 per woman above the age of 40, which is comparable with the general Dutch population (1.8) (28). Therefore, we concluded that having VWD does not result in fewer children. Our questionnaire did not distinguish between early and late foetal loss, therefore it is not possible to draw firm conclusions about the prevalence of foetal loss in our cohort. A very high number of women $(52 \%)$ needed curettage because of bleeding after pregnancy losses. This is in line with a previous study, in which also a high incidence of post-abortal bleeding was observed (29). In the general population the number of curettage after pregnancy loss was only 2-20\% (30). The high number of bleeding can partly be explained by the low FVIII and VWF levels in VWD, which do not rise significantly until the second trimester by which stage many foetal losses have already occurred $(31,32)$.

Our study has some limitations. First, the study design: we performed a retrospective study in which data were gathered using a self-completed questionnaire, and we have only self-reported data about menorrhagia and $\mathrm{PPH}$. Recall bias may be a potential problem. We determined the severity of menorrhagia and PPH using the Tosetto Bleeding Score and did not quantify blood loss for instance with the pictorial blood loss assessment chart (PBAC) score. However, data on the need of blood transfusion seem to be reliable and showed an increase in the VWD women compared to the general population. We defined menorrhagia as the presence of $\geq 2$ 
symptoms (see Table 1), based on available literature and recommendation of an international expert panel (13-15). Second, the Tosetto Bleeding Score used in this study was designed as a physician-administrated questionnaire and not for self-administration. However, patients with severe VWD and type 3 had higher bleeding scores, compared to patients with type 1 VWD and moderate VWD, suggesting that this self-completed questionnaire revealed reliable results. A third limitation is that the Tosetto Bleeding Score was originally developed only to distinguish between adult type 1 VWD patients and patients without VWD $(2,33)$. However, recently also others have successfully used the Bleeding Score in type 2 and $3 \operatorname{VWD}(34,35)$, and we think that this also reflects severity of bleeding phenotype in our cohort of patients.

The strength of our study is the large number of unselected women included. Our study covers almost all women with moderate and severe VWD in the Netherlands, since the large majority of all individuals who were diagnosed with moderate or severe VWD in any of the 13 Dutch Haemophilia Centres participated in the study. Therefore referral bias is limited, especially since our crosssectional study included all women, regardless of the presence of menorrhagia. Finally, central laboratory testing of VWF and FVIII levels was performed, excluding bias by inter-laboratory differences.

In conclusion, women with moderate or severe VWD frequently have menorrhagia in need of treatment, and a large proportion of the VWD women underwent a hysterectomy. Bleeding complications occur in over half of the women after childbirth or

\footnotetext{
Appendix: WiN collaborators

- Academic Medical Center, Amsterdam: K. Fijnvandraat, P.W. Kamphuisen;

- VU University Medical Center, Amsterdam:A. Kors, S. Zweegman;

- Netherlands Hemophilia Society, Badhoevedorp: M.E.L. DegenaarDujardin

- Amphia hospital, Breda: G.J. Goverde, M.H. Jonkers;

- Catharina hospital, Eindhoven: N. Dors, W.J.D. Hofhuis;

- Maxima Medical Center, Eindhoven: M.R. Nijziel;

- University Medical Center Groningen, Groningen: K. Meijer, R.Y.J. Tamminga;

- Kennemer Gasthuis, Haarlem: P.W. van der Linden;

- HagaZiekenhuis, The Hague: P.F. Ypma;

- Leiden University Medical Center, Leiden: J.G. van der Bom, H.C.J. Eikenboom, F.J.W. Smiers;

- Maastricht University Medical Center, Maastricht: B. Granzen, K. Hamulyák;

- Radboud University Nijmegen Medical Centre, Nijmegen: P. Brons, B.A.P. Laros-van Gorkom, I. Nováková

- Erasmus University Medical Center, Rotterdam: A. de GoedeBolder, F.W.G. Leebeek (principal investigator), E.M. de Wee (study coordinator)

- Van Creveldkliniek and hematology, University Medical Center, Utrecht: E.P. Mauser-Bunschoten (chair steering committee).
}

pregnancy loss. Progeny seems not to be affected in women with moderate or severe VWD.

\section{Acknowledgements}

The WiN study was supported by research funding from Dutch Hemophilia Foundation (Stichting Hemophilia) and CSL Behring (unrestricted grant). We thank all participating patients and all hemophilia nurses for their work on including patients.

\section{Conflict of interest}

Frank W. G. Leebeek is a member of the haemophilia advisory board of CSL Behring, and attended a round table meeting of Baxter. Jeroen C. J. Eikenboom received research support from CSL Behring. Karina Meijer and Eveline P. Mauser-Bunschoten are members of the haemophilia advisory board of CSL Behring. J.G. van der Bom has received unrestricted research/educational funding for various projects from the following companies: Bayer Schering Pharma, Baxter, ZLB Behring, Novo Nordisk, and Wyeth. In addition, she has been a consultant to Baxter and Whyeth, and she has been a teacher on educational activities of Bayer Schering Pharma. None of the other authors has a conflict of interest to declare.

\section{References}

1. Silwer J. von Willebrand's disease in Sweden. Acta Paed Scand 1973; 238: 1-159.

2. Tosetto A, Rodeghiero F, Castaman G, et al. A quantitative analysis of bleeding symptoms in type 1 von Willebrand disease: results from a multicenter European study (MCMDM-1 VWD). J Thromb Haemost 2006; 4: 766-773.

3. Kadir RA, Sabin CA, Pollard D, et al. Quality of life during menstruation in patients with inherited bleeding disorders. Haemophilia 1998; 4: 836-841.

4. Kouides PA, Phatak PD, Burkart P, et al. Gynaecological and obstetrical morbidity in women with type I von Willebrand disease: results of a patient survey. Haemophilia 2000; 6: 643-648.

5. Ragni MV, Bontempo FA, Hassett AC. von Willebrand disease and bleeding in women. Haemophilia 1999; 5: 313-317.

6. Kirtava A, Crudder S, Dilley A, et al. Trends in clinical management of women with von Willebrand disease: a survey of 75 women enrolled in haemophilia treatment centres in the United States. Haemophilia 2004; 10: 158-161.

7. Lethagen S, Hillarp A, Ekholm C, et al. Distribution of von Willebrand factor levels in young women with and without bleeding symptoms: influence of $\mathrm{ABO}$ blood group and promoter haplotypes. Thromb Haemost 2008; 99: 1013-1018.

8. Kadir RA, Economides DL, Sabin CA, et al. Assessment of menstrual blood loss and gynaecological problems in patients with inherited bleeding disorders. Haemophilia 1999; 5: 40-48.

9. Kirtava A, Drews C, Lally C, et al. Medical, reproductive and psychosocial experiences of women diagnosed with von Willebrand's disease receiving care in haemophilia treatment centres: a case-control study. Haemophilia 2003; 9: 292-297.

10. Sadler JE, Budde U, Eikenboom JC, et al. Update on the pathophysiology and classification of von Willebrand disease: a report of the Subcommittee on von Willebrand Factor. J Thromb Haemost 2006; 4: 2103-2114.

11. Nichols WL, Hultin MB, James AH, et al. von Willebrand disease (VWD): evidencebased diagnosis and management guidelines, the National Heart, Lung, and Blood Institute (NHLBI) Expert Panel report (USA). Haemophilia 2008; 14: 171-232.

12. Federici AB. Clinical diagnosis of von Willebrand disease. Haemophilia 2004; 10 (Suppl 4): 169-176.

13. James AH, Kouides PA, Abdul-Kadir R, et al. Von Willebrand disease and other bleeding disorders in women: consensus on diagnosis and management from an international expert panel. Am J Obstet Gynecol 2009; 201: 12 el-8.

14. Warner PE, Critchley HO, Lumsden MA, et al. Menorrhagia I: measured blood loss, clinical features, and outcome in women with heavy periods: a survey with follow-up data. Am J Obstet Gynecol 2004; 190: 1216-1223. 
15. ACOG practice bulletin: management of anovulatory bleeding. Int J Gynaecol Obstet 2001; 72: 263-271.

16. Salem RO, Van Cott EM. A new automated screening assay for the diagnosis of von Willebrand disease. Am J Clin Pathol 2007; 127: 730-735.

17. Smith DR, Murphy D. Capillary blotting of agarose gels. Methods Mol Biol 1996 58: 23-25.

18. Budde U, Schneppenheim R, Eikenboom J, et al. Detailed von Willebrand factor multimer analysis in patients with von Willebrand disease in the European study, molecular and clinical markers for the diagnosis and management of type 1 von Willebrand disease (MCMDM-1VWD). J Thromb Haemost 2008; 6: 762-771.

19. Sadler JE. A revised classification of von Willebrand disease. For the Subcommit tee on von Willebrand Factor of the Scientific and Standardization Committee of the International Society on Thrombosis and Haemostasis. Thromb Haemost 1994; 71: 520-525.

20. Foster PA. The reproductive health of women with von Willebrand Disease unresponsive to DDAVP: results of an international survey. On behalf of the Subcommittee on von Willebrand Factor of the Scientific and Standardization Committee of the ISTH. Thromb Haemost 1995; 74: 784-790.

21. Oehler MK, Rees MC. Menorrhagia: an update. Acta Obstet Gynecol Scand 2003; 82: 405-422.

22. Knol HM, Bogchelman DH, Kluin-Nelemans HC, et al. Routine evaluation and treatment of unexplained menorrhagia: do we consider haemostatic disorders? Eur J Obstet Gynecol Reprod Biol 2010; 152: 191-194.

23. Kadir RA, Chi C. Women and von Willebrand disease: controversies in diagnosis and management. Semin Thromb Hemost 2006; 32: 605-615.

24. Kouides PA. Current understanding of von Willebrand's disease in women - some answers, more questions. Haemophilia 2006; 12 (Suppl 3): 143-151.

25. Jansen AJ, van Rhenen DJ, Steegers EA, et al. Postpartum hemorrhage and transfusion of blood and blood components. Obstet Gynecol Surv 2005; 60: 663-671.
26. James AH, Jamison MG. Bleeding events and other complications during pregnancy and childbirth in women with von Willebrand disease. J Thromb Haemost 2007; 5: 1165-1169.

27. Eikenboom J, Fijnvandraat K. Behandeling van de ziekte van von Willebrand. In: Richtlijn: Diagnostiek en behandeling van hemofilie en aanverwante hemostasestoornissen 2009. pp. 115-126.

28. CBS. Central bureau of statistics. Statistics Netherlands. 2010; Available at http://www.cbs.nl/en-GB: Accessed August 24, 2010.

29. Kadir RA, Lee CA, Sabin CA, et al. Pregnancy in women with von Willebrand's disease or factor XI deficiency. Br J Obstet Gynaecol 1998; 105: 314-321.

30. Hamerlynck JV, Wieringa-de Waard M, Middledorp S. From the Cochrane Library: both expectant management and curettage are suitable options in case of miscarriage. Ned Tijdschr Geneeskd 2006; 150: 2750-2752.

31. Franchini M. Haemostasis and pregnancy. Thromb Haemost 2006; 95: 401-413.

32. Molvarec A, Rigo J, Jr., Boze T, et al. Increased plasma von Willebrand factor antigen levels but normal von Willebrand factor cleaving protease (ADAMTS13) activity in preeclampsia. Thromb Haemost 2009; 101: 305-311.

33. Rodeghiero F, Castaman G, Tosetto A, et al. The discriminant power of bleeding history for the diagnosis of type 1 von Willebrand disease: an international, multicenter study. J Thromb Haemost 2005; 3: 2619-2626.

34. Gill JC, Christopherson PA, Flood VH, et al.; The Zimmerman Program Investigators. Bleeding Scores in Von Willebrand Disease (VWD) Re-Visited: Analysis of the TS Zimmerman Program for the Molecular and Clinical Biology of VWD. ASH Annual Meeting Abstracts. 2008; 112: 425 (Abstract).

35. Federici AB, Mannucci PM, Castaman G, et al. Clinical and molecular predictors of thrombocytopenia and risk of bleeding in patients with von Willebrand disease type 2B: a cohort study of 67 patients. Blood 2009; 113: 526-534. 